\title{
Music performance anxiety in instrumental duos: six interviews
}

\section{A ansiedade de performance musical em duos instrumentais: seis entrevistas}

\author{
Fiammetta Facchini* \\ Ministry of Education, University and Research (MIUR) - High Artistic Formation, Musical and Choreutical (AFAM), Italy \\ fiammettafacchini@hotmail.com \\ Nancy Lee Harper** \\ University of Aveiro, Department of Communication and Art, Portugal \\ New University of Lisbon, Center for Studies of Sociology and Musical Aesthetics (CESEM), Portugal \\ nancy.leeharper@gmail.com
}

\footnotetext{
* Fiammetta Facchini is a Pianist and Professor of Piano and Chamber Music for several State Music Conservatories in Italy. Since 1999, she has been playing in a Violin-Piano Duo, Tramma-Facchini. She holds a PhD in Music Performance under the supervision of Professor Dr. Nancy Harper (University of Aveiro, Portugal). Her dissertation, Psycho-physio dynamics in violin-piano duo: a pianist's perspective, is available at https://ria.ua.pt/handle/10773/13820).

** Nancy Lee Harper has been described as "a multi-talented American musician and scholar" (Music \& Vision, Ray Picot). A retired Associate Professor with Aggregation at the University of Aveiro, Portugal, and a Researcher at the New University of Lisbon, at the Center for Studies of Sociology and Musical Aesthetics (CESEM), Portugal, Nancy is the author of several scientific articles and books (Iberian music, Piano Pedagogy, Music \& Medicine, Bahá'í academics). She has performed and taught on four continents and recorded CDs, including world premieres.
} 


\section{Abstract}

With the objective of analyzing the presence or absence of Music Performance Anxiety (MPA) in consolidated instrumental duos, six semi-structured interviews with members of three long-term instrumental chamber music duos (violin and piano; cello and piano; piano 4-hands duo) were conducted. The analysis showed that MPA is somewhat common to all the musicians, but that the "duo" was considered to be a safe place or place of refuge as compared to that of solo performance. The causes of MPA in duo performance for those interviewed were related to family and to the environment in which they were raised. In addition, a reluctance to speak about MPA between the duo members prevailed. The lack of an educational system to promote knowledge and to assist in the development of coping strategies was noted. Differing attitudes were observed across the generational gaps of the duos with regard to solving the problem of MPA. However, all agreed that a positive psychosomatic attitude and healthy lifestyle, coupled with the application of breathing techniques and concentration, are effective means to countering the problems of MPA. Regarding their perceptions of performing with the regular partner in a long-term or consolidated duo as opposed to an occasional partner in a short-term duo, all interviewees affirmed the preferred satisfaction that the long-term commitment gave, noting that it provided "another perception, another poetry".

Keywords: Instrumental Duos. Interviews. Music Performance Anxiety (MPA). Violin. Cello. Piano.

\section{Resumo}

Com o objetivo de analisar a presença ou a ausência de Ansiedade de Performance Musical (APM) em duos instrumentais consolidados, seis entrevistas semiestruturadas com membros de três duos instrumentais de música de câmara de longa duração (violino e piano; violoncelo e piano; piano a 4 mãos) foram conduzidas. A análise mostrou que a APM é um pouco comum a todos os músicos, mas que a formação de duo foi considerada um lugar seguro ou de refúgio quando comparado ao lugar da performance solo. As causas da APM na performance em duo, para os entrevistados, foram relacionadas à família e ao ambiente em que foram criados. Além disso, a relutância em falar sobre APM entre os membros dos duos prevaleceu, e a falta de um sistema educacional para promover o conhecimento e auxiliar no desenvolvimento de estratégias de enfrentamento foi observada. Diferentes atitudes foram observadas através das diferenças de gerações dos duos, no que diz respeito à resolução do problema da APM. No entanto, todos concordaram que uma atitude psicossomática positiva e um estilo de vida saudável, juntamente com a aplicação das técnicas de respiração e concentração, são meios eficazes para combater os problemas da APM. Em relação às suas percepções de desempenho com o parceiro regular em um duo de longo prazo ("duo consolidado"), em oposição a um parceiro ocasional em um duo de curto prazo ("duo ocasional"), todos concordaram com a satisfação preferencial do duo de longo prazo, apreciando nele "outra percepção, outra poesia".

Palavras-chave: Duos instrumentais. Entrevistas semiestruturadas. Ansiedade de Performance Musical (APM). Violino. Violoncelo. Piano. 


\title{
LITERATURE REVIEW
}

Although referred to by different terms - such as stage fright, stress, anxiety, performance nerves, performance jitters, and others - Music Performance Anxiety (MPA) has been the subject of many recent studies. For the purposes of this study, Music Performance Anxiety is characterized as:

\begin{abstract}
the experience of marked and persistent anxious apprehension related to musical performance that has arisen through underlying biological and/or psychological vulnerabilities and/or specific anxiety/conditioning experiences. It is manifested through combinations of affective, cognitive, somatic, and behavioural symptoms. It may occur in a range of performance settings, but is usually more severe in settings involving high ego investment, evaluative threat (audience) and fear of failure. It may be focal (i.e., focused only on music performance), or occur concomitantly with fears of other situations rather than music, such as social phobia. It affects musicians across the lifespan and is at least partially independent of years of training, practice, and level of musical accomplishment. It may or may not impair the quality of the musical performance. (KENNY, 2011, p.15)
\end{abstract}

Music Performance Anxiety (MPA) clearly takes the lead of all the factors that affect the quality of performance in solo and ensemble cases, both positively and negatively (EYSENCK; CALVO, 1992; PAPEGEORGI et al., 2007). Mal-adaptive MPA is considered one of the most common and most elusive problems affecting musicians (BRANDFONBRENER, 1999). In one study, more than $70 \%$ of orchestral musicians reported having had performances negatively affected by anxiety at least once during their careers (BRANDFONBRENER, 1999) and for $15 \%$ to $25 \%$ of all musicians, MPA became severe enough to the point of impairing their performances (STEPTOE, 2001).

Given the problem of negative MPA, studies have tried to understand these phenomena and to find possible prevention and coping strategies (NAGEL et al., 1989; ORMAN, 2004). Individual characteristics, repertoire and circumstances of performance have been deemed the most influential factors associated with MPA (VALENTINE, 2008; PAPAGEORGI et al., 2007). Solo performances are associated with higher levels of MPA than group performances (PAPAGEORGI et al., 2007) and performances involving auditions or examinations have been associated with higher MPA than rehearsals or concerts (LEHMANN et al., 2007). Even the MPA of soloist and audience has been measured (OLIVEIRA e SILVA et al., 2013). This is because one of the pieces interpreted was a work in three movements in which there was only silence (John Cage's 4'33"). The absence of sound and "normal music" could have been factors of anxiety for the listeners. In this case, an opposite response to the soloist's extremely high MPA was found in the audience. In other words, there was no MPA detected in the audience, even in these unusual circumstances.

Within the specific context of chamber music in general, studies have focused on varying problems that sometimes include the duo configuration. These studies embrace: rehearsal dynamics (DAVIDSON; KING, 2004; GINSBORG; KING, 2007), structure and organization of practice (GINSBORG et al., 2006), the musician's role in the rehearsal (KING, 2006), co-ordination between partners in performance (WILLIAMON; DAVIDSON, 
2002), social interactions between group members (FORD; DAVIDSON, 2003; KING, 2006; BLANK; DAVIDSON, 2007; MORAN, 2010;), musical interaction and negotiation techniques (DAVIDSON;GOOD 2002; DAVIDSON;KING, 2004), gender effects and "musical androgyny" (BLANK; DAVIDSON, 2007), physiological effects of duos on each other (FACCHINI et al., 2013); and modes of communication, including visual, gestural, aural, verbal and non-verbal communication (KING; GINSBORG, 2011; MOTA et al., 2013; VANDEMOORTELE et al., 2015, 2016, 2017; MORAN et al., 2017; WÖLLNER, 2018).

The professional, long-term duo offers a unique environment in which to explore many ideas. In our study, the fact that these musicians had stayed together provided a rich legacy of experience.

\section{RATIONALE}

Given the paucity of literature targeting consolidated long-term instrumental duos and MPA, the main purpose of this research study focused on answering the question: What are the opinions and views of consolidated duos on MPA and stress management during performance? By seeking answers to this principal question, it was hoped that conclusions would be drawn which could then be applied to a larger group of musicians.

\section{METHODOLOGY}

Qualitative research is undertaken because a problem or issue needs to be explored and because complex and detailed understanding of the subject under discussion is needed (CRESWELL et al., 2014; CLARK, 2007). Qualitative research is also used because quantitative measures and statistical analysis simply do not answer all the questions, or do not suit the problem. For KVALE (2003), the qualitative research interview seeks to describe and to highlight the meanings of central themes in the life world of the subjects. The main task in interviewing is to understand the meaning of what the interviewees say. According to Gianturco (2004), qualitative research is based on the importance of studying the facts, actions, norms and values of the participants, giving ample space to the perspective of those being studied. In other words, we try to look through the eyes of people whom we are studying. And, according to Tanggaard (2009, p. 1498), one major objective of qualitative research interviewing "is to identify general discursive repertoires in speaking within particular social settings and to fuel public dialogue about research themes beyond the specific interview setting".

For Lindlof \& Taylor (2010, p.3),

qualitative researchers interview people for several reasons: to understand their perspectives on a scene, to retrieve their experiences from the past to gain expert insight or information, to obtain descriptions of events that are normally unavailable for observation, to foster trust, to understand sensitive relationships, and to create a record of communication that can subsequently be analysed. 
According to Weiss (2008, p.11),

investigators who are attracted to the richness of materials produced by qualitative interview studies but concerned about what may seem to be their looseness sometimes conclude that fixed-question - open response interviewing provide a desirable compromise. Here respondents are asked carefully crafted questions but are free to answer them in their own words rather than required simply to choose one or another predetermined alternative.

Semi-structured interviews were chosen as these provided an opportunity for interaction, probing questions, and the flexibility to follow up on areas of interest (CORBETTA, 1999). Each interview lasted approximately forty minutes, during which the researchers attempted to retrieve as much detailed and thorough information on the subject as possible. The primary objectives were to access the perspective of the subjects studied, to try to glean their conceptual perspectives, and to understand their interpretations of their reality and the reasons for their actions/reactions (BURNARD, 1991).

\section{Participants and criteria}

There were six participants involved in this study, all internationally recognised professional musicians. Five were Italian and there was one Australian. One was the concertmaster of a leading orchestra in Italy. Several of the participants had made professional recordings. Among them, all have or have had a regular activity in instrumental duo. These participants included the members of three different instrumental duos, which are characterized as: (i) Violin and piano duo (husband and wife); (ii) Cello and piano duo (two brothers); and (iii) Piano 4-hands duo (husband and wife).

It was not very easy to find musicians who belonged to a long-term instrumental duo, who had substantial musical activity, and who were available to confess to and confront a concept that is still considered taboo by many musicians. The mere discussion of MPA became the topic that could reveal or prove a hypothetical fragility. That is, on the one hand, the empirical material which came from an interview through verbal expression might provide indications about the cognitive and behavioural sphere of the respondent through their attitudes (i.e. motivations, opinions, and behaviours). At the same time, non-verbal communication (i.e. body language, omissions in statements, etc.) could provide indications about the respondents' affective and emotional states.

The justification for the selection of the participants depended upon: (i) instrumental duo experience of a high professional level and (ii) a willingness to participate. Among the three duos, one has now retired from performing due to age. With the other two duos, there is approximately a two-generation difference from the retired one. Thus, an interesting and very different perspective emerged from answers given to the same questions.

In order to protect their anonymity, the participants are fictitiously identified as:

- Duo 1 (D1). Violin and Piano Duo - Pianist (Francesca), Violinist (Andrea);

- Duo 2 (D2). Cello and Piano Duo - Pianist (Giovanni), Cellist (Mario);

- Duo 3 (D3). 4-hands Piano Duo - Pianist (Isabella), Pianist (Rodolfo). 
It can be seen that in two of the duos, four musicians performed on four separate instruments, whereas in the third duo (piano 4-hands), there was only one instrument shared between them.

\section{Interview Study design and procedures}

The literature on conducting interviews is extensive (JARRAT,1996; WENGRAF, 2001; LONGHURST, 2003; BONI; QUARESMA, 2010). The interview cannot be considered a simple technique for gathering information because it is more a process of interaction between two individuals: the interviewer and the interviewee. To ensure that the interviews were semi-structured and characterised by flexibility, ten points by Corbetta $(1999$, p. 423) were followed. These are: 1. Preliminary explanations; 2. Primary questions; 3. Probe questions; 4. Repetition of the question; 5 . Repetition of the response; 6 . Encouragement, expressions of interest; 7. Pause; 8. Request for further explanation or elaboration; 9. Tactic of theme change; 10 . Role of the interviewer.

The interview was organized into four blocks of questions, preceded by a brief identification of the respondent. These are described below.

1. The first set of questions was used to establish a profile of the duo. This included questions to understand better how the duo began, what type of activity and repertoire it had, as well as to find out if any recordings had been made and/or if any new works were dedicated to the duo.

2. The second set of questions was conducted in order to know if the people involved in the duo had (or have) problems with MPA on stage and if, during their career, they were able to identify situations that normally caused anxiety.

3. The third set of questions was designed to see if there was a space inside the duo to talk about MPA and, if so, on what terms.

4. Finally, the fourth and final set contained questions related to possible techniques used to solve the problem of anxiety on stage.

In order to carry out the qualitative interviews, the following structure was used:

- Identification of the theoretical framework: what to study and with what expectations;

- Identification of the characteristics of the universe of the subjects (chamber musicians);

- Identification of the individual respondents;

- Definition of the type of interview to be conducted;

- Preparation of the interview guideline;

- Unfolding and recording of the interview;

- Transcript of the interview;

- Analyses of all interviews according to key words and phrases;

- Presentation of findings, and discussion of results.

The semi-structured interview format allowed for flexibility and follow-up, depending on the individual's responses. In fact, in some cases, the desire and need to 
spontaneously develop some argument or some unexpected nuance of the argument sometimes occurred. This led to a better understanding of the subject interviewed.

\section{Materials}

To carry out the interviews, a script of semi-open questions was specifically devised for this study. This script was based on the four main topic groups listed above. All interviews were recorded and filmed with a SONY video camera (model HDR-CX116), placed at a fixed angle that would be less noticeable by the interviewee. No separate audio recording was made.

\section{Transcribing the interviews}

In order to study more than the verbal context of the interviewee, a videotape recording was made of all the interviews. Both signed permission by the interviewee and ethics approval from the sponsoring university were obtained. Anonymity was guaranteed for the participants. After the interview, a complete verbatim (word for word) transcription was made. This transcription kept all comments, exclamations, and pauses intact, since it was considered that any change would have resulted in a translation of the text. Moreover, a system of graphic symbols was developed in order to be able to record the nonverbal conversation. For this purpose, the following abbreviations or symbols were used, according to Corbetta (1999) and Gianturco (2004):

- $\mathrm{FF}=>$ researcher / interviewer;

- $\mathrm{XX}=>$ interviewed;

- line space between the two rounds of word;

- , , ;! ? => to indicate the intonation;

- [ ] brackets for adding facial expressions, laughter, etc.;

-... => hesitation, brief pauses;

- UPPER CASE LETTER => high volume;

- lower case letter => low volume.

Below are two examples of transcription of interviews:

I. MB. NO, ABSOLUTELY NOT. I WAS THERE AND I WAS EXPECTING TO BE CALLED OUT AND WENT TO THE GALLOWS!!! [expression of terror] (Francesca D1)

II. AS. I can't explain why ... You think how much rumination we have in the brain, the sensitivity... [shakes his head] (Andrea D1).

\section{Analysing the Data}

The interviews were analysed systematically, having been concluded one by one. Later, the interviews were transcribed, translated (having been conducted in Italian), and catalogued with the introduction of symbols that assisted in finding commonalities and differences and in interpreting the content of the text. This type of analysis was 
corroborated with a professional psychiatrist (FR) who accompanied the study. Once all the interviews had been completed (six in total) according to the system described above, they were re-examined as a single group. As the ultimate aim was to understand the reactions of people in relation to MPA, the analyses were focused on the narrow sense of the subject, like a case study, which in turn gave the approach a holistic touch. Although the analysis of empirical material is supported by ad hoc software such as NVivo, Atlas.ti and HyperRsearch - programs that are part of Computer Assisted Qualitative Data Analysis Software (CAQDAS) - it was decided to analyse manually, thereby concentrating on the individual characteristics and any common threads, unexpected or unforeseen, which emerged during the interviews.

The presentation of the interviews was conducted in narrative form, i.e. through accounts, episodes, or description of cases, many times using or incorporating the same words used by the interviewees. In this way, an effort was made not to change the collected material or interview guideline so as to convey to the reader the immediacy of the situations presented, keeping in mind the principle objectives. Afterwards, the interviews were further analysed by the psychiatrist who accompanied this research study.

Demazière \& Dubar (1997) individuated different types of analysis:

- Analysis of the content;

- Thematic analysis;

- Analysis of the social knowledge of subjects;

- Transparent Analysis;

- Propositional analysis of discourse and relations for the opposition.

According to Demazière \& Dubar (1997), there are three possible types of analysis. These are:

1 - Illustrative Content analysis (objective description, systematic and quantitative analysis of the concepts expressed by the interviewee) and thematic analysis (splitting the content of the interview themes).

2 - Returning analysis (analysis of the social knowledge of the subjects) and analysis transparent for the understanding of social phenomena (the words of the respondents are sufficient, without the need for interpretation).

3 - Analytical analysis (discourse analysis and reports for opposition, which is based on key concepts of speech and of an overall structure at the base of each speech).

In the first case - illustrative analysis - the quotations from respondents are used to describe the claims of the researcher. Obviously, the risk of this type of analysis is that the interviewer can transform citations into an instrument of confirmation of her opinion.

An example of illustrative analysis is the following:

...This may also be an explanation of the difficulty in finding people even today willing to confront and talk about this subject matter because many are worried, considering it a shame. In fact, the first duo declared that they did not share among themselves or with other colleagues. This attitude seems to hide a background of generosity by not wanting to be a problem for another. 
So, in the internal illustrative analysis we have the analysis of the content and of the theme.

From thematic analysis we can isolate a series of themes and sub-themes forming a scheme within which each interview is read. Again, the risk is that the interviewer can use the material to support a hypothesis or thought according to her own inclination. According to the approach of returning analysis, the word of the respondents alone is considered able to provide, in a more transparent way, the means to understand the phenomena.

An example of returning analysis is from D3:

But in the difficulty, I must say that ... alone as I say my difficult times were between 24 and 28 years old, those were very difficult moments. But it was just a problem of identity, I did not know who I was then and I have also been lucky because, from a certain point of view, this uneasiness made me realize that I had to work on certain things, that my relationship with the music was taken very much for granted.

Finally, the analytical attitude makes an analysis of the material by considering prepositions, nouns and pronouns which are considered as semantic units, and assumes that they structure the cognitions of the subject. In this work, illustrative analysis (to illustrate) and returning analysis, in the sense to offer, through the words of the interviewee, a returned image of the person, were preferred. In this way, statements and common themes could be isolated, thereby allowing for a useful sense of understanding the problems connected with the fear/anxiety of performance.

\section{RESULTS}

From this analysis of six interviews, it clearly emerged that MPA was common to all the participating musicians. This was evident despite there being variations of intensity due to the mental attitude and personality of the individuals, and their circumstances. Interestingly enough, it was found that one of the duo members seemed to suffer more than the other. In other words, there was always one who had a more complex path or had more difficulty in tackling the problem of MPA. Although MPA did not always have a negative impact on the performance, there existed the possibility of jeopardising the group work. And even knowing that MPA could have an impact on performance quality, these musicians continued to develop a remarkable career from an international artistic standpoint. In fact, the highly anxious individual did not necessarily demonstrate impaired or inferior performance compared to that of lower anxious individuals (STRAHAN \& CONGER, 1998). Additionally, we realized that the price to pay for performing can sometimes be very high, as noted by one interviewee:

To play in public is like to walk on [a] thread, without protection, and with [the] wind [blowing]. (Francesca D1)

In this small study, it is interesting to consider that the past history of each duo may have some impact on the level of perception of its own anxiety, and especially the way 
the anxiety is perceived. Both musicians of the first interviewed duo $\left(D_{1}\right)$ expressed their experiences of transitioning from live concerts to recordings, which, despite not having the same perfection as the recordings of today, were a mark of strong comparison with the imperfection of the reality of live performances. Therefore, they both spoke of the changing of the idea about "perfection" and of loss of charm that:

...one can spring beyond the failed notes... (Andrea $\mathrm{D}_{1}$ )

For $\mathrm{D}_{1}$, radical changes concerning MPA occurred when the performances were recorded, for without a recording there was only the memory and emotion of the experience.

When the first recordings began, the comparison of the takes gave rise to anxiety... also if at first it [anxiety] did not exist, the improved listening apparatus became another source of it [anxiety] and what was done [the recording], was done. But whoever listened to it in the concert [the mistake] had to put up with it... and what remained were the reminiscences of the artist and the evening... Today, the ear no longer tolerates any wrong notes. (Andrea $\left.\mathrm{D}_{1}\right)$

In the case of $D_{1}$ there was a kind of passive acceptance of MPA because there was neither knowledge nor technique to address the problem. In the other duos, they instead noted the fact that the stage became an amplifier of their being. Consequently, in the case of the fear of the stage that exists, one should direct the fear in a way so as to benefit from the experience. This stage fright, for many, remains a cause of suffering.

Concerning this matter, the interviews reveal some very strong and especially touching statements. One of the pianists, a gold medallist at the Royal College of Music in London, who played a large solo repertoire and was also devoted to the world of chamber music, described her MPA in a clear and exhaustive statement:

... although, I repeat, I love music very much, I do not love the performance so
much, of being on stage. I do not have a single memory of a concert to be able
to say: "ah! How nice, I didn't suffer!" Personally, I do not think I was born to
be on stage. So it was always a little unnatural for me, because I had no desire
to expose myself. For me, it was waking up in the morning and already feeling
something in my stomach ... Although my husband said that I did not seem to be
tense. (Francesca $\mathrm{D}_{1}$ )

Similarly, the pianist of the Cello and Piano Duo $\left(D_{2}\right)$, who is self-described as having been "shy" for many years from adolescence to the early years of his professional career, openly declared himself to have suffered deeply from stage anxiety. This interviewee offered an even more complete view of his inner life and of his attitude towards the difficulty with the stage by declaring that he lived in a situation of "conflict".

Yes, undoubtedly, I suffered ... to me, it has always been a relationship of conflict between the pleasure of playing and of suffering... (Giovanni $D_{2}$ )

The pianist of the 4-hands Duo (Rodolfo $D_{3}$ ) summed up his position in these words: 
... I suffered from fears ... with which I had to fight a lot... it was always a bit of a fight ... a great fight. The result, we say was not invalidating but for me was, in any way, the result of suffering... (Rodolfo $\mathrm{D}_{3}$ )

Curiously, these three interviewees had a quite different attitude from the MPA of their partners. This difference leads us to think that each of these three duos had found a kind of balance in this sense, i.e. compensation. One of them, a concertmaster of an important Italian orchestra during much of his career, recognized some "small problem" of stage anxiety, but admitted that anyway there wasn't anything that he couldn't control and face.

... Of course, yes, a little tension but acceptable, that may be faced ... (Andrea $\mathrm{D}_{1}$ )

In more or less the same way, the cellist of $\mathrm{D}_{2}$ showed much more daring compared to his pianist brother in relation to the stage. He said that he never suffered great anxiety, even while acknowledging that there could be variations of anxiety related to different situations.

I never had major anxieties ... yes, the arch will tremble sometimes but very rarely... (Mario $\left.\mathrm{D}_{2}\right)$

One pianist of the 4-hands Duo $\left(D_{3}\right)$, who had been a child prodigy, had never had trouble playing even as an adult. Yet, when she was facing a destructive personal relationship with another musician (pianist) with whom there was strong competition, she began experiencing stage fright. In other words, the start of MPA coincided with the time of her becoming a mature adult.

... I started to have problems serious enough from the point of view of stage fright, those were truly difficult times ... but ... today, when we played in duo, I never happen to have problems of stage fright. (Isabella $\mathrm{D}_{3}$ )

\section{Emergent themes}

One of the aspects that has emerged spontaneously from almost all respondents speaking about anxiety/stress in performance was the variance of the sensation of anxiety as related to different situations. Virtually all respondents compared the situation of experience of playing solo with playing chamber music. In other words, all interviewees, spontaneously were found to suffer more in the situations in which they were playing solo rather in the duo because of the familiarity that developed over the years with their partner, the quality of the preparation and because of sharing the stage "together". That is, through the fact of being two (people), especially for the subjects who suffered more on the stage, the duo itself represented a kind of anchor that gave strength, and which serves and has served as a life buoy:

... the fear has been halved as compared to having to play the Rachmaninov concerto from memory, just me, or the "Emperor" [Beethoven's 5th piano concerto] and have him [her husband] near me. It was a great sense of comfort, because we were "together". (Francesca $\mathrm{D}_{1}$ ) 
Another participant agreed about the stress of solo performing as an adult:

... no, never as a child. After, some minor problem. The worst feeling for me is in the solo with the orchestra, not with the duo... (Andrea $\mathrm{D}_{1}$ )

Yet another participant had a similar feeling about solo performing:

... it is easier for me to play in a duo, very simple... yes, because it's something l've always done [chamber music] while the solo concert is something that happens rarely ... in duo, I must say, we go forward more, unless I feel [the stress of the stage]; now it's just a joy to come and play. Yes, it's beautiful... (Mario $\mathrm{D}_{2}$ )

A fourth participant agreed about the safety net of the duo as compared to solo performing:

... in the duo I feel safe... when we played in a duo I did not ever happen to have problems with stage fright. It sometimes happens to me that I experience shaking when I play alone, especially when I had little time to study, yes. But in a duo I feel protected. (Isabella $\mathrm{D}_{3}$ )

A fifth participant echoed these sentiments:

... generally, my fears were always stronger as a soloist. In all experiments the chamber music was always relaxed but much quieter, with the exception of a few moments of difficulties with people with whom I played or when the repertoire was very challenging, perhaps studied in a short time. So perhaps a bit of stress due to the preparation... (Rodolfo $\mathrm{D}_{3}$ )

To sum up, Table 1 presents a comparison between the perceptions of MPA when playing solo or within a duo. For each duo, we can observe that one member-musician suffered more from MPA than the other. Only in one case, the female pianist of the 4-hands duo affirmed that she had no problem with MPA in duo performance.

\begin{tabular}{|c|c|c|}
\hline Participants/Duo/ Instrumentalist & MPA in solo performance & MPA in duo performance \\
\hline Francesca $\left(D_{1}\right)$ Violin and Piano Duo - Pianist & Yes & Yes \\
\hline Andrea $\left(D_{1}\right)$ Violin and Piano Duo - Violinist & Some \\
\hline Giovanni $\left(D_{2}\right)$ Cello and Piano Duo - Pianist & Yes & Yes \\
\hline Mario $\left(D_{2}\right)$ Cello and Piano Duo - Cellist & Some & Few \\
\hline Isabella $\left(D_{3}\right)$ 4-hands Piano Duo - Pianist & Few (but already had) & Some \\
\hline Rodolfo $\left(D_{3}\right)$ 4-hands Piano Duo - Pianist & Yes & Some \\
\hline
\end{tabular}

Table 1. Respondents' answers concerning MPA, in solo performance and in duo performance.

\section{Suffering and Sharing}

Bearing in mind that duo performance can be regarded as a privileged environment, it was necessary to know if, within this exclusive environment, there was space to share the problem of anxiety on stage between duo members. When looking at the responses 
concerned with the sharing of MPA experiences or talking about this problem with the partner and/or other colleagues, the results seemed to indicate meaningful difference in the attitudes of the first and oldest duo, that it was normal to suffer on stage. It was a perfectly natural reaction and this was almost a price to pay for being on stage. One should suffer for one's Art.

No, I didn't speak ... I thought, "it is so, I do this work and it is so". (Francesca $D_{1}$ )

This attitude was spoken of as if this was, indeed, an element of discrimination and selection of nature. In other words, the musician who could not withstand the pressure of the stage had not enough talent and was therefore automatically eliminated. An association between stage fright and a kind of weakness was recognised.

...to admit that I have a significant amount of MPA would be, in the eyes of others, a weakness. As I said, this is more a problem with the orchestra than with the duo. $\left(\right.$ Andrea $\left.D_{1}\right)$

This may also be an explanation of the difficulty in finding duos willing to talk about MPA; many still deal with shame of having it. In fact, the first duo stated that they did not share their stage fears among themselves or with other colleagues. This attitude seems to hide a background of generosity by not wanting to be a problem for the other, in this case, the partner in performance.

...there were times in which there was no talk of these things... no, I did not want to talk to him [her husband] about my stage fright, because I thought that he had his problems too. (Francesca $\mathrm{D}_{1}$ )

Thus, the problem remains within each performer, although in very different forms and intensities, throughout their entire career. In fact, the pianist never remembered a concert in which she had not suffered. But this attitude also did not allow her to know, despite their being husband and wife, if her husband suffered from stage fright and to what extent.

... I do not think my husband suffered less. But I'm not sure because he never hinted. (Francesca $\mathrm{D}_{1}$ )

Interesting is the position of her husband (the violinist of $D_{1}$ ), who claims, on the contrary, to suffer a little from anxiety, but it was nothing that he could not control or face. It also seems to be an interesting statement in which he acknowledges that, in any way, especially in the role of first violin of an orchestra, he must maintain a strong image:

$$
\text { I... couldn't let myself go ... (Andrea } \mathrm{D}_{1} \text { ). }
$$

Regarding the other four interviews, it is important to remember that all are within a similar age group and younger than $D_{1}$. In $D_{1}$, MPA was acknowledged but not shared within the duo and even less with colleagues. In the other duos, the problem of MPA, 
although present in varying degrees, was treated and eventually solved. The attitude of sharing happened to all participants in $D_{2}$ and $D_{3}$. This occurred almost exclusively within the familiarity of the duo and very rarely with colleagues in whom they found a great deal of reluctance in talking about it, even difficulty in admitting the existence of this fear because of the stigma of shame associated with MPA.

In the 4-hands Piano Duo $\left(D_{3}\right)$, there was a rare case of complete sharing within duo members. This was owing to the particular individual path taken.

... [this] is a theme that is part of our history: so, it would be a contradiction to be embarrassed in talking about it. (Rodolfo $\mathrm{D}_{3}$ )

...we are very close ... so if there are concerns we always share them. (Isabella $D_{3}$ ) project:

The $D_{3}$ was founded after many years of friendship and the realization of a common

...with the creation of a Music Academy, we found a space where we have been able to integrate wisdom and empirical knowledge of ancient traditions such as Yoga, meditation techniques, breathing and more modern disciplines like Neuro-Linguistic Programming (NLP), Feldenkrais or Alexander techniques, Mind-mapping etc... (Isabel $\mathrm{D}_{3}$ )

Only after that, in fact, did they form the instrumental duo, marrying a few years later, and maintaining their professional duo. It seems obvious that, for this duo, facing this kind of MPA issue is part of their personal lives.

In relation to speaking with other colleagues about MPA, a different kind of attitude was expressed. This difference might perhaps be explained by the physical nature of instruments.

In this regard, Rodolfo and Isabella $\left(D_{3}\right)$ say:

... with some people yes [to speak about MPA], I do, and with others no, because they are completely resistant to this thing, especially the violinists. Because even with the singer, in this aspect there is much looseness ... probably because what they have to do with consciously breathing is simpler, because the breath in itself is one of the most important keys for me ... (Rodolfo $\mathrm{D}_{3}$ )

... [it] is already a lot when someone can admit to being afraid ... (Isabella $D_{3}$ )

With some variations, in the Cello and Piano Duo, $\mathrm{D}_{2}$, there is an openness towards the other, but in a less direct way and only within the family:

... until I was in the school it was easy for me to open myself up to my friends/ classmates ... but when I crossed the threshold of the profession, to share the problems lays you a little bare, I found it to be much, much harder. (Giovanni $\mathrm{D}_{2}$ )

However, within the family, which consists of many brothers who are all musicians, the pianist managed to find a valve for sharing, especially with one brother who is curiously not the cellist partner but another brother:

... he is one that has undergone the stage further than me. (Giovanni $D_{2}$ ) 
The cellist of $D_{2^{\prime}}$, however, has a different attitude. He goes a little further and thinks that since he has always known his brother and shared so much with him, that everything which is happening to him is known and understood; as such, it is not necessary to verbalize much.

...we do not talk so often because there is not this need. (Mario $\left.D_{2}\right)$

While the pianist affirmed that his brother

...in general, he always suffered less than me ... (Giovanni $\mathrm{D}_{2}$ )

Also, he proved to be aware of and to be able to recognize their levels of anxiety as he felt the differences experienced in performing with his brother. These levels were transformed and experienced as something positive. In other words, with the support of his brother who could offer security, he said:

... this aspect helped me with it [MPA] ... playing predominantly with him facilitated me in addressing the audience and the stage. (Giovanni $\mathrm{D}_{2}$ )

The cellist brother affirmed his conviction that it is important to help others with their own peacefulness:

...In my opinion, you set an example, it is something that is done naturally and therefore during the moments in which you offer a bit of your tranquillity to the other, the other calms down. (Mario $\mathrm{D}_{2}$ )

To summarise, the responses of the six interviewees were quite different. Basically, three positions relative to this question are found in the duos' responses: 1) a position of concern for the other; 2 ) a more positive attitude by trying to be as quiet or reticent as possible about MPA, convinced that this attitude is helpful to the partner in performance; and 3) a position of acceptance of the other's difference. The concern for the other, evidences a desire that things can go well for the other person, considered to be a little more fragile emotionally, because the experience of this performance is rewarding and satisfying, and because the performance can reward the efforts and sacrifices made to get there. The reaction to become quieter in front of the other's anxiety expresses the acceptance of the other's differences and the wish to help the other by adopting the most serene stance.

... [it does] not solve much talking about trying to help someone else with their own tranquillity. (Mario $\mathrm{D}_{2}$ )

... when these moments happen, my reaction is...to try to calm myself more. Paradoxically, for me, the other people's tension calms me. (Rodolfo $\mathrm{D}_{3}$ )

Yet, in this case Rodolfo $\left(D_{3}\right)$ does not speak about the consolidated duo but about the collaborations that are more or less occasional, albeit with some regularity. The 
person who cares about the other is concerned with the fact that the person who is suffering can overcome the obstacles and can therefore achieve his/her desired quality performance. In other words, the wish is that the experience of performance is positive and that it has positive repercussions on the performer's self-esteem.

In Table 2, one can see clearly the different opinions of the interviewees on the importance of sharing MPA with the partner in performance and with other musician colleagues. It seems evident that is not easy to speak with other colleagues about MPA and that the position with the own partner is quite broad, from no sharing to complete sharing.

\begin{tabular}{|c|c|c|}
\hline Participants/Duo/ Instrumentalist & Sharing (MPA) within Duo & $\begin{array}{c}\text { Sharing (MPA) with } \\
\text { other colleagues }\end{array}$ \\
\hline Francesca $\left(D_{1}\right)$ Violin and Piano Duo - Pianist & No & No \\
\hline Andrea $\left(D_{1}\right)$ Violin and Piano Duo - Violinist & No \\
\hline Giovanni $\left(D_{2}\right)$ Cello and Piano Duo - Pianist & Rarely & No \\
\hline Mario $\left(D_{2}\right)$ Cello and Piano Duo - Cellist & Rarely \\
\hline Isabella $\left(D_{3}\right)$ 4-hands Piano Duo - Pianist & Yes & Yes (but others are not always \\
\hline Rodolfo $\left(D_{3}\right)$ 4-hands Piano Duo - Pianist & Yes & Yes (but others are not always \\
available)
\end{tabular}

Table 2. Capacity and willingness to share MPA experiences with own partner and other musician colleagues.

\section{The possible causes of anxiety and stage performance}

Another question related to MPA was asked about possible associated causes. One primary consideration may be to establish the source of our fears. Probably the possibilities are infinite because one can discuss matters which range from childhood to what the performer eats on the day of the concert, or the individual relationship with music, emotions, judgment by others, comparison with others, the balance and energy of the body and other possible causes. So, to organise this endless palette of causes in a general scheme becomes an extremely difficult task. Thus, it might be more constructive to try to understand the inner dynamics, the way in which a person thinks, feels, behaves, and acts in public. As one pianist of the 4-hands Duo recalled,

$N L P$ teaches that people create movies in their heads that lead to fear and then they obey the automatic schemes learned. (Rodolfo $D_{3}$ )

The most important thing is therefore to learn to recognize these problems and then to change them, since this involves a good deal of self-consciousness and self-observation.

One could say that the true cause of fear is lack of self-knowledge and how the mind works, an ignorance of the creative mechanisms of perception and attention. (Rodolfo $\mathrm{D}_{3}$ )

It could be interesting, in this aspect, to try to think of the meaning that Aristotle gave to the principle of "cause", which is not only the "because" - that is, the origin 
of something but also its purpose; in other words, the reason that the cause happens (TODOROV, 1979). Thus, "stage fright" or "performance anxiety" could be seen as the origin of the phenomena and its purpose for happening.

It could be more useful to ask ourselves what we do with fear, how each individual interacts with its sensations and experiences, instead of asking ourselves how we can transform it. Obviously, this is a deeply personal journey that cannot be generalized. Therefore, fear might be related to the way in which, and the ability with which each individual manages him/herself. For the pianist of the 4-hands duo, this management can be that the musician looks for an experience in music, something of which he/she is not always conscious. In that sense, a musician is looking for something whereby he/she can transcend him/herself, but since he/she is not very aware, he/she comes into conflict with him/herself.

$$
\text { Fear ... is fear that others are unaware of what we can be. (Rodolfo } D_{3} \text { ) }
$$

But it is clear that this is an attachment to a picture of oneself that:

$$
\text { ...prevents the flow that it is necessary to live music, to play it ... (Rodolfo } D_{3} \text { ) }
$$

According to his colleague, the fear of performance, based on personal experience as a teacher, depends in $80-85 \%$ of cases, on two factors:

the first due to a poorly done study and the second to an inability to manage physically. (Isabella $\mathrm{D}_{3}$ )

For her, the problem also lies in the fact of being isolated, of carving out a space to live alone. In addition, the fault would be found in shifting the goal of making music and transmitting values instead to one that is focused on the self and not the music. Isabella believes that many people, especially young people, are afraid to perform because they are

...much more important than the music. Making a good impression in front of others is much more important than what they are playing. (Isabella $\mathrm{D}_{3}$ )

Other reasons may be an inability to predict in the study or learning phase what will happen during performance, or to rely upon automation or procedural memory without thinking during the performance that levels of attention, concentration, breathing change, and/or other factors can interfere with or betray procedural memory. Based on her personal experience as a teacher and pianist, she says:

I notice that often ... [a person] who is very anxious, without fixed physical positive sensations, doesn't nourish the well-being with attention and therefore isn't able to reproduce it. (Isabella $\mathrm{D}_{3}$ )

It appears that the participants experienced the change in circumstances between practice and performance as detrimental. However, one participant felt there was a choice to control one's attitudes. 
... I can decide how I feel, the place to consider myself a victim of something stronger and powerful than me. (Isabella $\mathrm{D}_{3}$ )

As for the aspect of possible interference and family to influence the development of our fears, this may be questioned when we observe that, in the case of the duo of brothers, we have two very different reactions although they have grown up in the same environment, with only four years apart, and have the same parents. This shows that the environment has not prevented a very different attitude towards performance. This may indicate that the personality characteristics of everyone and, especially, the way in which we decide to relate to problems will have a fundamental weight in the development and attitude of performance anxiety.

Table 3 presents a summary of the opinions about possible causes of anxiety. Irrespective of age, all participants interviewed think that bad preparation, judgment of the other, lack of musical beliefs and the personality characteristics are the strongest reasons for MPA to develop.

\begin{tabular}{|c|c|c|c|c|c|}
\hline Participants/Duo/ Instrumentalist & \multicolumn{5}{|c|}{ Opinion on the possible causes of anxiety } \\
\hline & $\begin{array}{c}\text { The lack of } \\
\text { preparation }\end{array}$ & $\begin{array}{c}\text { Judgment } \\
\text { of the other }\end{array}$ & $\begin{array}{c}\text { Management of } \\
\text { one's own body }\end{array}$ & $\begin{array}{c}\text { The lack of musical } \\
\text { beliefs }\end{array}$ & Personality \\
\hline Francesca $\left(D_{1}\right)$ Violin and Piano Duo - Pianist & $\mathrm{X}$ & $\mathrm{X}$ & - & $\mathrm{X}$ & $\mathrm{X}$ \\
\hline Andrea $\left(\mathrm{D}_{1}\right)$ Violin and Piano Duo - Violinist & $\mathrm{X}$ & $\mathrm{X}$ & - & $\mathrm{X}$ & $\mathrm{X}$ \\
\hline Giovanni $\left(\mathrm{D}_{2}\right)$ Cello and Piano Duo - Pianist & $\mathrm{X}$ & $\mathrm{X}$ & $\mathrm{X}$ & $\mathrm{X}$ & $\mathrm{X}$ \\
\hline Mario $\left(\mathrm{D}_{2}\right)$ Cello and Piano Duo - Cellist & $\mathrm{X}$ & $\mathrm{X}$ & $\mathrm{X}$ & $\mathrm{X}$ & $\mathrm{X}$ \\
\hline Isabella $\left(\mathrm{D}_{3}\right)$ 4-hands Piano Duo - Pianist & $\mathrm{X}$ & $\mathrm{X}$ & $\mathrm{X}$ & $\mathrm{X}$ & $\mathrm{X}$ \\
\hline Rodolfo $\left(\mathrm{D}_{3}\right)$ 4-hands Piano Duo - Pianist & $\mathrm{X}$ & $\mathrm{X}$ & $\mathrm{X}$ & $\mathrm{X}$ & $\mathrm{X}$ \\
\hline
\end{tabular}

Table 3. The summary shows the interviewees' thoughts about the possible causes of MPA. Only by the youngest duo was the management of the body not mentioned.

\section{DISCUSSION}

\section{Attempts to solve the problem}

In the analyses of the six interviews, it emerged that there were manifold attempts to solve the problem of MPA, with the exception of $D_{1}$ (Violin and Piano Duo). They did not attempt to solve the problem and did not acknowledge its existence to the other. They simply thought they should live with it and try to accept what this suffering was. They were convinced that this was "normal", and that suffering was part of this activity. Even so, despite this position of an almost "passive acceptance", this duo considers that there are four elements needed to overcome anxiety when it may be a risk factor of jeopardising the quality of the performance: (i) being well prepared; (ii) knowing each other well; (iii) having support from each other; (iv) making a loving search for excellence.

To summarize, the participants of $D_{1}$ seemed to acknowledge that it would be of great help to have confidence in their preparation, to be aware that they were doing a good job, to have a good knowledge of the partner, and to know that unconditional support could be counted on. Additionally, they seemed to want to have a loving musi- 
cal search in the preparation phase and to look for something to convey together to the audience. This conviction, shared by the other participants who also put the quality of the preparation in first place before the performance and the need to have very clear ideas about what they were playing, is something that represents an element of strength in order to avoid maladaptive anxiety.

I must say that the great job that we do and the fact that we have very clear ideas about what we're playing, being very convinced of what is being proposed, is for me/us extremely important ... (Mario $\mathrm{D}_{2}$ )

While one of the pianists of the 4-hands duo, who was for many years trying to cope with MPA, admitted that there was not much space, if any, to create a kind of "free" performance "in the moment", summarised her feelings in these words:

... I had to put aside anxiety and create, in any way, a kind of execution that was standardized and could, in any case, operate and which represented me.... yes it was hard to surrender to the moment... I was always studying a lot ... to create a preparation so strong that I could play in public a type of performance that corresponded to me. (Rodolfo $\mathrm{D}_{3}$ )

The common opinion of respondents is also that even if it is found that probably the fear never disappears completely, it can undoubtedly be addressed consciously and constructively. MPA, then, can become

... a thrill to turn and not eliminate. (Giovanni $\left.\mathrm{D}_{2}\right)$

In addition to this attitude, the Cello and Piano Duo practise yoga daily and have done for many years (from the early 1980s) and believe that it helps their physical, mental, and emotional control enormously at the moment of entering the stage. The pianist also said that for some time, because of being too overwhelmed with multiple tasks in various directions as a pianist, teacher, concert organizer, etc., he had decided to eliminate this daily practice of yoga. However, he admitted, "it was wrong", because the situation began to get out of control again. So, he decided to resume practising yoga and also includes daily meditation, because for both musicians this life habit is something extremely important.

One member of this duo admitted:

... the experience of teaching, anyway, facilitates ... to understand the problem from different points of view and therefore to understand that one can make a route that can be followed forward, one which can solve the problems. (Giovanni $\left.\mathrm{D}_{2}\right)$

In the case of the pianists' duo, to use the words of one of them: 
Thus, the viewpoint of having too little ego creates a situation of a passive victimization. If there is too much ego, then the situation becomes an excessive narcissism, which can also be destroyed by the judgment of others. The ideal situation seems to be a viewpoint in which introspection, self-analysis, research, and recognition of emotions are recognized to be fundamental in addressing the problem of anxiety and, over time, in finding a solution.

The 4-hands Piano duo, which had also undergone different experiences on a personal level through work in the Avatar Course using techniques of active imagination, relaxation, etc., (the most "powerful" course, to use the words of the female pianist), affirms that to work on one's self is an experience in which one feels

...that there is a transformation between before and after. (Isabella $D_{3}$ )

This has changed the lives of both very much simply because this course provided them with the tools to manage the focus of energy and attention. These tools have also been important in their work as teachers, to help students to find their capacities to improve the relationship with one's own body.

... I realized how important it was to have a focused study, to be in touch with your body in a certain way ... my relationship with music has really become a relationship of great pleasure. (Isabella $\mathrm{D}_{3}$ )

For the pianist it thus becomes extremely important to have fifteen/twenty minutes of mental preparation before the concert, or whatever a person does in those moments before going on stage. Especially, she thinks that the "presence of mind" is a very significant and important factor because the mind is entangled in disabling images. And this translates into something mental and physical welfare, a kind of physical preparation

because I should feel good physically ... and certainly I don't stay sitting in a chair ... (Isabella $\mathrm{D}_{3}$ )

Table 4 presents a summary of the above-mentioned techniques used by the participants to cope with MPA.

\begin{tabular}{|c|c|c|c|c|}
\hline Participants/Duo/ Instrumentalist & \multicolumn{3}{|c|}{ Techniques used to tackle stage fright } \\
\hline & Yoga & Avatar & Meditation & Others (Feldenkreis/ Alexandre/etc.) \\
\hline Francesca $\left(D_{1}\right)$ Violin and Piano Duo - Pianist & - & - & - & - \\
\hline Andrea $\left(D_{1}\right)$ Violin and Piano Duo - Violinist & - & - & - & - \\
\hline Giovanni $\left(D_{2}\right)$ Cello and Piano Duo - Pianist & $X$ & - & $X$ & - \\
\hline Mario $\left(D_{2}\right)$ Cello and Piano Duo - Cellist & $X$ & - & $X$ & - \\
\hline Isabella $\left(D_{3}\right)$ 4-hands Piano Duo - Pianist & - & $X$ & $X$ & $X$ \\
\hline Rodolfo $\left(D_{3}\right)$ 4-hands Piano Duo - Pianist & - & $X$ & $X$ & $X$ \\
\hline
\end{tabular}

Table 4. The first duo (the oldest duo) did not use any technique to overcome MPA. On the contrary, the two younger duos are open to speaking about, sharing and experimenting with different techniques to try to solve the problem. 


\section{MPA differences between consolidated and occasional duos}

Another important aspect that was highlighted in almost every interview, and spontaneously, was the following: there seem to be qualitative differences in the reports with regard to how participants express their experiences of MPA, especially between the long-term consolidated duo situation and another of a short-term occasional duo. In the case of the older Duo $\left(D_{1}\right)$, the pianist said:

... it is surely beautiful to be a duo and also be a family. No doubt ... I think that it is a GREAT thing ... For us, the word duo means many things. It means a great harmony, as well as two individual people. We are still here to experience the same things, to look at a good film and cry at the same things... and we are always so much music lovers. (Francesca $D_{1}$ )

Even the more radical husband violinist said:

The duo as a hierarchical structure makes no sense: the duo is only such when it's just family. The duo should be a loving pair who loves and creates a sense of fluidity in the moment ... stays close and no one can play like you. (Andrea $\mathrm{D}_{1}$ )

In the same way, another interviewee puts the accent on the difference between playing with one's partner and playing more or less frequently with other people:

There are synergies that create a unit of different things with different people with whom you are dealing. (Rodolfo $D_{3}$ )

The same opinion was shared by the cellist who is happy to be still rehearsing (a phase he considers to be even more beautiful than the performance itself) with his brother with whom he has the privilege of having shared thirty years of concerts, from an early age, aware that this is something extremely rare:

...when we played together ... there is another air onstage compared to when we did a concert with another person ... (Mario $\mathrm{D}_{2}$ )

In this regard, this opinion is almost always shared by the musicians who make chamber music like a philosophy of life based on sharing and complementarity. This recalls a wonderful affirmation by violinist Elisa Pegreffi (the second violin of the famous Quartetto Italiano), who during an interview, said that somebody once said to her that there was another quartet which, contrary to her own (they used to spend the entire day rehearsing together), held few rehearsals and performed in public just the same. She merely smiled and said:

Well...listen to it! (Pegreffi) ${ }^{1}$

\footnotetext{
$1 \quad$ Elisa Pegreffi was the second violin of Quartetto Italiano, a famous string quartet founded in 1945. Carpi when all four players were still in their early 20s. They were originally named Nuovo Quartetto Italiano before dropping the "Nuovo" in 1951. They are particularly noted for their sound, their recording of the complete cycle of Beethoven string quartets - made between 1967 and 1975 and for their playing by memory.
} 
With that stated, it is clear that occasional chamber music with non-regular partners has nothing to do with groups working together for a long time. The fact is that only people who make a career of this kind may be able to recognize a group that works in a certain way. The importance of good rehearsal strategies and clear performance cues seem to be the keys to the success of new duos (GINSBORG; BENNETT, 2015, p. 129-130). Otherwise, on the contrary, the musicians who do not perform in stable or consolidated groups will not be able to notice the difference.

In addition, the pianist of the 4-hands Duo, which considers itself privileged to be able to share music also as a couple and which finds something beautiful and wonderful in it, thinks that in the Duo she feels safe. She declares that their duo is:

a journey, a challenge ... we never stop, it is a continuous challenge ... and... the goal is not only to be good with the music and propose the music of the heart; it also releases into the environment a little bit of clean air ... because we have to understand that a musician today in society is a tremendous resource. (Isabella $\left.\mathrm{D}_{3}\right)$

To empower and to be able to communicate at a much deeper level, emotionally, to find a more intimate contact, to help the person to open up, to look to their own resources with confidence, is undoubtedly something positive to offer to our society, something which is greatly needed. And this sharing, as stated by the partner, represents the point of the duo's strength. Thus, this duo is sharing on many levels, not only a musical one. They clearly are aware:

...that music and life are not two separate realities ... (Rodolfo $D_{3}$ )

Thus, in this aspect, the fact of sharing a life on a personal level creates a kind of advantage. The pianist (male) says the same:

I think it is not so simple for many others because if you do not make music a survey of life ... then communication becomes a little different ... because it communicates on different levels. (Rodolfo $\mathrm{D}_{3}$ )

That (level of communication) is shallower. So when he plays with his usual pianist partner, Rodolfo declares himself to have a sense of "harmony and fullness", while with others he sometimes feels "a difficulty" but can also feel "moments of challenge, moments of very strong stimulus". The big difference between the stable Duo and the other is synthesized in this sentence:

When I play with her ... I feel at home ... (Rodolfo $D_{3}$ ) 


\section{FINAL CONSIDERATIONS}

\section{I.}

Following the analysis of our sample of 6 related musicians, it seems they all experience MPA and view it as something common in music. For these musicians interviewed, chamber music and especially performing in a duo is a refuge or a safe place where they feel protected. They found that the highest tension in relation to stage fright occurs on two occasions: (i) performing solo and (ii) under-preparing, or, when the preparation had not been suitable or was considered to be insufficient in whatever way.

\section{II.}

Regarding the causes of MPA in duo performance, in this sample, the family and the environment or context in which the musician grew up were reported to have had an impact. Many studies have been done on assessing and treating childhood anxiety, with findings that suggest the best early treatment is preferentially found in Cognitive Behaviour Therapy, and pharmacology as a second option as needed (CRESWELL et al, 2014; WEHRY, 2015; VALLANCE \& FERNANDEZ, 2016). Personal characteristics also have a large impact on the development and intensity of MPA. As observed from the duo of the two brothers from the same family, very different reactions about performance and anxiety existed despite their growing up in the same environment. This finding corroborates a similar finding in a study comparing twins in childhood to non-twin siblings: "We...conclude that genetically-influenced traits of children impact upon their sibling interactions, but that, unlike other family relationships, sibling dynamics are primarily characterized by reciprocity" (MARK et al, 2017). There is also an interconnection with other familial relationships, such as parents or care-givers (ENGER, 1988). Therefore, we can deduce that a sensitive and carefully observant attitude on the part of those who deal with the process of growth and the development of young musicians - be they family members and/or pupils - can help them to make the personal journey in a way that is the most suitable for their individual characteristics.

\section{III.}

There also emerged from the interviews the absence of an education system, at least where our interviewees are concerned (in Italy), which promotes knowledge and the development of coping strategies to deal with MPA. This need is regarded as urgent by the participants since this kind of education can help a person to search inwardly about the causes of MPA and how to manage it, both the somatic and psychological reactions.

Yet in all of this, what has not been explained is the disparity in treatment between that provided for musicians and the attention paid to, for example, professional sports people. Why is it that for decades we have become accustomed to the fact that it is 
imperative for a professional sports person to have a personal trainer, massage therapist, and psychologist to accompany him/her almost every day, whereas a musician is left alone, abandoned and confined to his/her space to deal with his/her own body and enormous emotions? It is up to the musician's personal initiative to decide on a path of analysis and insights, absent of any guidance, and usually with a huge earning discrepancy from that of the sports star.

In this respect, it would be desirable in the course of musical learning and training that much more attention be paid to the self-awareness of one's own body and emotions, and, not least, to the quality of lifestyle, diet included. Considering the claims of the respondents, these elements would represent a positive result in the quality of their own life experience in relation to the stage and performance. During their professional careers, the younger two duos have seen the necessity for this awareness and have been able to incorporate some helpful practices. On the strictly personal level, more confidence and self-awareness would be possible by overcoming these impediments. Imagine practising or training always under supervision, as a sports person does, and then receiving immediate feedback. The easiest, although perhaps not optimal, way that we have for instant feedback is to record or videotape our performances on our smart phones. There are some music teachers today who do not permit the child to practise alone at home, but always with the teacher so that bad habits are not inculcated. This kind of education is usually found amongst singing or string teachers (especially violin teachers since the violin with its high pitch so close to the child's ear could cause damage) but not others. Supervised practice, as with the sports model, has been shown to be more efficient: "a highly organised and systematic regimen of supervised practice is an effective means of improving musical performance" (BARRY, 1992).

Regarding the attempts to solve the problem of MPA, we find that respondents mostly appear to agree that several things constitute an effective means to counteract the problems of performance anxiety. A positive psychosomatic attitude, a healthy lifestyle and the application of breathing techniques and concentration are practices, which, if done in a rational and conscious way, seem to assist in controlling MPA. The same duo who has never tried a technique (because at the time "there was no talk [even] minimally" of these problems) and passively accepted this suffering (D1) recognized that being well prepared, knowing the piece well, considering the other to be secure, and having made a loving study of the content are dependable weapons to counter the anxiety of performance.

It is clear that bad management of one's own body includes incorrect physical attitudes, locked or overly protected muscles or muscular tension (for example, locked or raised shoulders; lifting your shoulders for tension in the legs or the neck muscles; or simply holding your breath). Unfortunately, there are few examples of teaching based on proprioception, or self-knowledge. In other words, it could be more useful to decide how we feel and act by using effective strategies for doing so.

Personally, the authors believe that the teacher's attitude towards this aspect is crucial. When the teacher or the "Maestro" is seen as our guide - not only musical but spiritual - and we have great admiration for him/her, the message that the teacher can 
pass to us becomes crucial in our experiences with, and before, the performance. Relatively speaking, the moment that is, after all, only a moment of our lives, is one of the steps. Another is to learn to know one's body and our own somatic reactions in order to be able to learn to control them and manage them. However, this rarely is taught or discussed in an educational path. Often teachers, who may be frustrated with their career options, stopped playing or left a career because of MPA. Or, in the odd case, they may be people who have not suffered much on the stage and therefore have never confronted this problem and are not able to turn to help others.

\section{IV.}

Regarding the perception of "difference" between the consolidated duo compared to occasional duos, all are agreed that in fact there is, on stage, a "different air" when one has played for a long time with a person and has developed a special relationship, like husband and wife or as brothers as

two people who know each other, know how to breathe, know the defects, etc. are able to achieve a special amalgamation which becomes a unique personality. (Andrea $D_{1}$ )

As an interviewee observed in the comparison of the occasional duo to the consolidated duo (the former of which may consist of two great soloists who are occasionally together),

...there is no poetry, or charm. (Andrea $D_{1}$ )

This interviewee belongs to a duo that has worked for a long time on lovingly searching for the details to make a performance become something special and privileged where communication between the two is based on a series of thoughts, opinions and details that have been chosen, reflected and matured over time. Wrongly, according to respondents, we think that anything that

...is made in two is turned into a duo. (Andrea $\mathrm{D}_{1}$ )

In this context, the aspect of "sharing" is seen as something extremely important for development not only as musicians but also as human beings. The saying "divide and conquer", in which everyone stays in their own small corners, is a safer path than the contrasting one of opening up to change. The former presents the loss of opportunity to evolve and therefore nurtures "our fears", as stated by the pianist of the 4-hands Duo.

To conclude, the authors would open a small parenthesis emphasizing that the opportunity of "sharing", which chamber music offers, is without comparison. It is undoubtedly a special and wonderful land, an area to which more space within (and beyond) the training of musicians should be given, especially if we acknowledge the extremely powerful social values that belong to it. 


\section{Limitations and Future Applications}

The small number of participants in this study, by its very nature, is limiting. The specific qualifications of the participants somewhat added to the difficulty in recruiting individuals, since the study was limited to members of long-term duos who were willing to talk about MPA.

Future applications would be to apply this study to a larger number of participants of consolidated duos, similar to the Blank \& Davidson study (2007), and to extend it to other countries. It could even be applied to other long-term performing duos outside classical music. Another future aspect to add to the current interview questions would be to ask what impact the exploding recording and media industries (YouTube, Spotify, others) have had on live performance with regard to increased or decreased MPA (PHILIP, 2004; MORTIMER et al, 2012).

This study was undertaken as a segment of a larger, multi-disciplinary study, part of which has been published (FACCHINI et al., 2013). The larger study observed psycho-physiological aspects of violin-piano duos, both consolidated and occasional, with special emphasis on the pianist's perspective (FACCHINI, 2013). Several components comprised the study. These were:

- measurement of heart rate variables in pre-performance and performance situations by using a long-term wearable Holter-type T-shirt;

- measurement of physiological stress levels through cortisol testing in pre- and post-performance situations with a partner change (occasional, short-term duo) that was created for the study and that presented extreme performance situations to the musicians;

- psychological tests for the three performing musicians;

- interviews with the consolidated and occasional violinists;

- analysis of the pianist's diary; and

- interviews with consolidated duos. Through these investigatory techniques, this multi-disciplinary study had some unexpected findings.

The main outcome revealed that physiological stress and psychological MPA levels were higher with members of the long-term consolidated duo, because they "aimed high" and had a lot at stake in their performances due to their reputation as performers and recording artists. The occasional duo of the study, although it too aimed for excellence, had much little to gain or lose, and was less stressful since it was a temporary ensemble created for the study with little at stake and no future direction. The long-term consolidated duo represented an entity with its own identity that grew and evolved.

\section{References}

BARRY, N. The Effects of Practice Strategies, Individual Differences in Cognitive Style, and Gender upon Technical Accuracy and Musicality of Student Instrumental Performance, Psychology of Music, v.20, n.2, p. 112-123, 1992. 
BLANK, M.; DAVIDSON, J. An exploration of the effects of musical and social factors in piano duo collaborations. Psychology of Music, v. 35, n. 2, p. 231-248, 2007.

BONI, V., \& Quaresma, S. J. Aprendendo a entrevistar: como fazer entrevistas em Ciências Sociais. Em Tese, v. 2, n.1, p.p. 68-80, 2010, https://periodicos.ufsc.br/index.php/ emtese/article/view/18027/16976 retrieved 13 June 2018.

BRANDFONBRENER, A. Performance anxiety: Different strokes for different folks. Medical Problems of Performing Artists, v.14, n.3, p.101-102, 1999.

BURNARD, P. A method of analysing interview transcripts in qualitative research. Nurse education today, v. 11, n. 6, p.p. 461-466, 1991.

CLARK, D. B.; AGRAS, W. S. The assessment and treatment of performance anxiety in musicians. The American journal of psychiatry, v. 148, n. 5, p. 598-605, 1991. DOl: https://doi.org/10.1176/ajp.148.5.598.

CORBETTA, P. Metodologia e tecniche della ricerca sociale. Bologna: Il Mulino, 1999.

CRESWELL, C.; WAITE, P.; COOPER, P. J. Assessment and management of anxiety disorders in children and adolescents. Archives of Disease in Childhood, v. 99, n.7, p. 674-678, 2014. http://adc.bmj.com/content/archdischild/early/2014/03/17/archdischild-2013-303768.full.pdf, retrieved 13 June 2018.

DAVIDSON, J. W.; GOOD, J. M. Social and musical co-ordination between members of a string quartet: An exploratory study. Psychology of Music, v. 30, n. 2, p. 186-201, 2002.

DAVIDSON, J. W.; KING, E. C. Strategies for ensemble practice. In: WILLIAMON, A. (Ed.), Musical excellence. Strategies and techniques to enhance performance. Oxford: Oxford University Press, p. 105-122, 2004.

DeMAZIERE, D.;DUBAR, C. Analyser les entretiens biografiques. Paris: Ed. Nathan, 1997.

ENGER, A. The interrelatedness of marriage and the mother-child relationship. In: HINDE, R. A.; HINDE, J. S. (Eds.), Relationships within families: mutual influences. Oxford: Oxford University Press, p. 104-118, 1988.

EYSENCK, M. W.; CALVO, M. G. Anxiety and performance: The processing efficiency theory. Cognition \& Emotion, v. 6, n. 6, p. 409-434, 1992. 
FACCHINI, F. Psycho-physio dynamics in Violin-Piano Duo: A Pianist's Perspective. Unphblished PhD dissertation, Universidade de Aveiro, Portugal, http://ria.ua.pt/bitstream/10773/13820/1/tese.pdf, 2013.

FACCHINI, F.et al. Beating Together: A Case Study of Heart Rate in Partners Change in Violin \& Piano Duo In: WILLIAMON, A.; GOEBL, W. Proceedings of the International Symposium on Performance Science 2013, Brussels, Belgium: European Association of Conservatoires (AEC), p. 337-342, 2013.

FORD, L.; DAVIDSON, J. W. An investigation of members' roles in wind quintets. Psychology of Music, v.31, n.1, p. 53-74, 2003.

GIANTURCO, G. L'intervista qualitativa. Dal discorso al testo scritto. Milano, Guerini e Associati, 2004.

GINSBORG J.; CHAFFIN R.; NICHOLSON G. Shared performance cues in singing and conducting: A content analysis of talk during practice. Psychology of Music, v. 34, n.2, p. 167-192, 2006.

GINSBORG, J.; KING, E. The roles of expertise and partnership in collaborative rehearsal. In: WILLIAMON, A.; COIMBRA, D. In:. WILLIAMON, A.; COIMBRA, D. (Eds.), Proceedings of the International Symposium of Performance Science 2007. Utrecht, The Netherlands: European Association of Conservatoires (AEC), p. 69-74, 2007. ISBN 9789090224848.

GINSBORG, J.; BENNET, D. Developing Familiarity: A New Duo's Individual and Shared Practice Features and Performance Cues. In: WILLIAMON, A.; MIURA, M, Abstracts of the International Symposium of Performance Science. Kyoto, Japan: Ryukoku University, p. 129-130, 2015.

JARRATT, D. G. A comparison of two alternative interviewing techniques used within an integrated research design: a case study in outshopping using semi-structured and non-directed interviewing techniques. Marketing Intelligence \& Planning, v. 14, n.6, p. 6-15, 1996.

KING, E. C. The roles of student musicians in quartet rehearsals. Psychology of Music, v. 34, n. 2, p. 262-282, 2006.

KING, E.; GINSBORG, J. Gestures and glances: Interactions in ensemble rehearsal. In: KING, E.; GRITTEN, A. (Eds.), New perspectives on music and gesture, p.177-201, 2011.

KVALE, S. The psychoanalytic interview as inspiration for qualitative research. Qualitative research methodology, v. 3, p. 29-83, 2001. 
LEHMANN, A. C.; SLOBODA, J. A.; WOODY, R. H. Psychology for musicians: Understanding and acquiring the skills. Oxford University Press, 2007.

LINDLOF, T. R; , TAYLOR, B. C. Qualitative communication research methods, Sage Publications, London, U.K., 2010.

LONGHURST, Semi-structured interviews and focus groups. In: CLIFFORD, N; COPE, MEGHAN; GILLESPIE, T.; FRENCH, S., Key methods in geography. London: Sage Publications, p. 117-132, 2003.

MARK, K. M. et al. Using twins to better understand sibling relationships. Behavior Genetics, v.47, n.2, p. 202-214, 2017. DOI: https://doi.org/10.1007/s10519-016-9825-z, retrieved 13 June 2018.

MORAN, N. Improvising musicians' looking behaviours: Duration constants in the attention patterns of duo performers. In: DEMOREST, S.; MORRISON, S.; CAMPBELL, P.S. (Eds.), Proceedings of the 11th International Conference on Music Perception and Cognition (ICMPC11). Seattle, Washington, United States: 2010 ICMP11, p. 23-27, 2010. http://depts.washington.edu/icmpc11/ICMPC11_ABSTRACTS.pdf retrieved 10 June 2018.

MORAN, N.; JAKUBOWSKI, K.; KELLER, P. E. Improvising Duos - visual interaction collection, 2011. [24 mp4 moving image clips]. University of Edinburgh, 2017. DOI: http:// dx.doi.org/10.7488/ds/2153, retrieved 10 June 2018.

MORTIMER, J. H.; NOSKO, C.; SORENSEN, A. Supply responses to digital distribution: Recorded music and live performances. Information Economics and Policy, v. 24, n. 1, p. 3-14, 2012. DOI: https://doi.org/10.1016/j.infoecopol.2012.01.007, retrieved 14 June 2018.

MOTA, D.; LOUREIRO, M.; LABOISSIÈRE, R. Analysis of synchronization patterns in clarinet duos using acoustic and kinematic parameters. In: SHIFRES, F.; PAZ, M; GONNET, D.; BURCET, M.I.; HERRERA, R. (Eds.), Actas de ECCoM, Buenos Aires: SACCoM, v.1 n.1, p.199-206, 2013. http://www.saccom.org.ar/actas_eccom/vol1-1_contenido/ mota_loureiro_y_laboissiere.pdf, retrieved 10 June 2018.

NAGEL, J. J.; HIMLE, D. P.; PAPSDORF, J. D. Cognitive-behavioural treatment of musical performance anxiety. Psychology of Music, v.17, n.1, p.12-21, 1989.

OLIVEIRA E SILVA, J. F et al. Performing Together? A case study of physiological stress between soloist and audience. In: WILLIAMON, A.; GOEBL, W. (Eds.), Proceedings of the International Symposium on Performance Science 2013, Brussels, Belgium: European Association of Conservatoires (AEC), p. 523-528, 2013. ISBN 9782960137804. 
PAPAGEORGI, I.; HALLAM, S.; WELCH, G. F. A conceptual framework for understanding musical performance anxiety. Research Studies in Music Education, v. 28, n. 1, p. 83-107, 2007.

PHILIP, R. Performing Music in the Age of Recording. London: Yale University Press, 2004.

ORMAN, E. K. Effect of virtual reality graded exposure on anxiety levels of performing musicians: a case study. Journal of Music Therapy, v.41, n.1, p.70-78, 2004.

STEPTOE A. Negative emotions in music making: The problem of performance anxiety. In: JUSLIN, P. N.; SLOBODA, J. A. (Eds.), Music and emotions: Theory and research. Oxford: Oxford University Press, p. 291-307, 2001.

STRAYHAN, E.; CONGER, A. J. Social anxiety and its effects on performance and perception. Journal of Anxiety Disorders, v.12, n. 4, 293-305, 1998.

TANGGAARD, L. The research interview as a dialogical context for the production of social life and personal narratives. Qualitative Inquiry, v. 15, n. 9, p. 1498-1515, 2009.

TODOROV, S. Metafisica di Aristotele. Roma: Ed. Bulzoni, 1979.

VALENTINE, E. La paura dell'esecuzione. L'esecuzione musicale, $2^{\circ}$ ed, San Donato (MI): Grafiche Pulsar s.r.l., p. 207, 2008.

VALLANCE, A.; FERNANDEZ, V. Anxiety disorders in children and adolescents: Aetiology, diagnosis and treatment. British Journal of Psychological Advances, v. 22, n.5, p.335344, 2016. DOI: 10.1192/apt.bp.114.014183, retrieved 13 June 2018.

VANDEMOORTELE, S. et al. How do musicians manage melody transfers when rehearsing chamber music? A study of their gaze behavior, Conference paper at ESCOM Conference 2017, IPEM, University of Ghent, Belgium, 2017. https://www.researchgate. net/publication/319188446_How_do_musicians_manage_melody_transfers_when_ rehearsing_chamber_music_A_study_of_their_gaze_behaviour, retrieved 10 June 2018.

VANDEMOORTELE, S. et al. Studying musicians' gaze behaviour in the light of synchronisation issues in ensemble playing, Conference paper 2016, Making Time in Music, University of Oxford, U.K, 2016. https://www.researchgate.net/publication/319188186_Studying_musicians'_gaze_behaviour_in_the_light_of_synchronisation_issues_in_ensemble_playing, retrieved in 10 June 2018. 
VANDEMOORTELE, S. et al. Into the wild - Musical communication in ensemble playing. Discerning mutual and solitary gaze events in musical duos using mobile eye-tracking, Conference paper, International Workshop on Vision and Eye Tracking in Natural Environments and Solutions \& Algorithms for Gaze Analysis, Bielefeld, Germany, 2015, https://www.researchgate.net/publication/284693486_Into_the_wild_-_Musical_communication_in_ensemble_playing_Discerning_mutual_and_solitary_gaze_ events_in_musical_duos_using_mobile_eye-tracking, retrieved 10 June 2016.

WEHRY, A.M. et al. Assessment and treatment of anxiety disorders in children and adolescents. Current Psychiatry Report, v.17, n.7, p.591- 606, article 52, 2015. DOI: 10.1007/s11920-015-0591-z retrieved 13 June 2018.

WEISS, R. Learning from strangers. The art and method of qualitative interview studies. New York: The Free Press, 1994.

WENGRAF, T. Qualitative research interviewing: Biographic narrative and semi-structured methods. London: Sage Publications, 2001.

WILLIAMON, R. A.; DAVIDSON, J. W. Exploring co-performer communication. Musicae Scientiae, v. 6, n. 1, p. 53-72, 2002.

WÖLLNER, C. Call and response: Musical and bodily interactions in jazz improvisation duos. Musicae Scientiae. [Article first published online: May 8, 2018]. DOI 10.1177/1029864918772004, 2018. 